\title{
INTERNATIONAL REVIEW OF ECONOMICS
}

AND MANAGEMENT

\section{ŞEHİRLERARASI OTOBÜS FİRMALARININ ULAŞILABİLİRLİĞİNİN MEMNUNIYET, FİRMA İTİBARI VE ALGILANAN DEĞER ÜZERİNDEKİ ETKİSİ}

\author{
Fatih Koç* \\ Mustafa Günalan ${ }^{\dagger}$ \\ Volkan Özbek ${ }^{\ddagger}$ \\ Binnaz Çinar ${ }^{\S}$
}

\section{Özet}

$\mathrm{Bu}$ çalışmanın amacı, şehirlerarası otobüs firmalarının sundukları hizmetlerin ulaşılabilirlik, algılanan değer, firma itibarı ve memnuniyet değişkenleri kapsamında ele alınmasıdır. Bu amaç doğrultusunda, ilgili değişkenleri içeren bir model geliştirilmiştir. Model, firmaların ulaşılabilirliğinin firma itibarı, algılanan değer ve memnuniyet üzerindeki etkilerini ölçmeyi amaçlamaktadır. Ayrıca, firma itibarı ve algılanan değerin memnuniyet üzerindeki etkileri de bu çalışma kapsamında ele alınmıştır. Çalışma için ihtiyaç duyulan veriler Balıkesir Üniversitesine bağlı ve Edremit Körfezi olarak ifade edilen coğrafi bölgedeki meslek yüksekokullarından toplanmıştır. Toplam 355 anket dikkate alınarak analizler yapılmıştır. Analizler SPSS ve AMOS programları kullanılarak gerçekleştirilmiştir. Yapılan analizler sonucunda, ulaşılabilirliğin itibar ve algılanan değer üzerinde etkili olduğu ancak, memnuniyet üzerinde doğrudan etkili olmadığı sonuçlarına ulaşılmıştır.

Anahtar kelimeler: Ulaşılabilirlik, Algılanan Değer, Firma İtibarı, Müşteri Memnuniyeti, Otobüs İşletmeleri.

JEL Kodu: M31, L83.

\footnotetext{
* Kocaeli Üniversitesi, Kandıra Uygulamalı Bilimler Yüksekokulu, fatih.koc@kocaeli.edu.tr

† Balıkesir Üniversitesi, Havran Meslek Yüksekokulu, mustafagunalan@yahoo.com

‡ Balıkesir Üniversitesi, Burhaniye Uygulamalı Bilimler Yüksekokulu, vozbek@balikesir.edu.tr

§ Balıkesir Üniversitesi, Sosyal Bilimler Enstitüsü,Uluslararası Ticaret ve Pazarlama ABD Yüksek Lisans Öğrencisi, binnazcinar62@gmail.com
} 


\title{
THE EFFECTS OF INTERCITY BUS COMPANIES' ACCESSIBILITY ON SATISFACTION, FIRM REPUTATION AND PERCEIVED VALUE
}

\begin{abstract}
The aim of this study is to investigate the intercity bus companies in terms of accessibility to their services, perceived value, firm reputation, and satisfaction. In accordance with this purpose, a model including these variables was developed. The model aims to measure the effects of service accessibility on firm reputation, perceived value, and satisfaction. In addition, the effects of firm reputation and perceived value on satisfaction was examined. The data of the research was gathered from students of Balıkesir University's some Vocational schools that are located in Edremit Gulf. In analyses of the data, a total 355 questionnaires were considered. Analyses were made by using SPSS and AMOS programs. The results of analyses demonstrated that service accessibility has effects on reputation and perceived value but doesn't has any effect on satisfaction.

Keywords: Accessibility, Perceived Value, Firm Reputation, Customer Satisfaction, Bus Companies.
\end{abstract}

JEL Classification: M31, L83.

\section{GíRİş}

Son yıllarda hava ve demir yolu gibi diğer ulaştırma seçeneklerinde ciddi gelişmeler olmasına rağmen, Türkiye' de hali hazırda en fazla kullanılan yolcu taşımacılığı türü kara yoludur (www.tuik.gov.tr). Hem devletin altyapı olanaklarını geliştirmesi hem de firmaların kendilerini teknoloji ve sunulan hizmet anlamında modernize etmesi bu yolcu taşıma türünü etkin kılmıştır. Özellikle hava ve demir yolu ulaştırma seçeneklerinin geliştirilmesi ile birlikte yolcu taşımacılığında rekabet farklı türler arasında da yaşanmaya başlamıştır. Bu açıdan bakıldığında, çok yoğun rekabetin yaşandığı yolcu taşımacılığı alanında firmaların müşteri istek ve ihtiyaçlarını karşılayacak çeşitli uygulamalara gitmeleri önemlidir. Bu noktada otobüs işletmelerinin çeşitli çabalarını görmek mümkündür. Yılmaz (2012) çalışmasında, otobüs işletmelerinin daha profesyonel hizmet vermeye başlamasından ve çeşitli konularda (yer ayırma işlemleri, tarifeler, otobüslerin teknik donanımı ve yan hizmetler gibi) kendini geliştirmesinden bahsetmiştir.

Bir yolcunun yıl içerisinde çok sayıda seyahat gerçekleştireceği düşünüldüğünde, otobüs firmalarının memnun müşteri elde etmeleri son derece önemlidir. Çünkü memnun müşteri tekrar satın alma olasılığı yüksek olan kişidir (Churchill \& Surprenant, 1982). Buradan hareketle bu çalışmada, otobüs işletmeleri için memnuniyetin belirleyicileri olabilecek değişkenler ele alınmıştır. 
$\mathrm{Bu}$ belirleyiciler; ulaşılabilirlik, algılanan değer ve firma itibarı değişkenleridir. Literatürde algılanan değer ve firma itibarının memnuniyet üzerindeki doğrudan veya dolaylı etkileri birçok çalışmada incelenmiştir (Loureiro \& Kastenholz, 2011; Sengupta, Balaji, \& Krishnan, 2015; Bolton \& Drew, 1991). Ancak, otobüs işletmeleri için ele alınan değişkenler arasındaki öngörülen ilişkiler bu çalışmanın özgün yanıdır. Ayrıca bu çalışmada, ulaşılabilirlik değişkeninin memnuniyet üzerindeki olası doğrudan etkisi de test edilmeye çalışılacaktır.

$\mathrm{Bu}$ çalışmada otobüs firmaları için kolay iletişim kurma, telefonla hizmetlere kolay ulaşma, bekleme süresinin uzun olmaması, hizmetin uygun saatlerde sunulması ve hizmetin sunum alanının uygun bir yerde olması ulaşılabilirliği ifade etmektedir. Ayrıca, yeni gelişen teknolojiler sayesinde internet ve mobil uygulamalar otobüs firmalarının ulaşılabilirliğini artıran diğer etkilerdir. $\mathrm{Bu}$ çalışmada, ulaşılabilirlik değişkenini ifade eden bu yapıların algılanan değeri ve firma itibarını artırıcı yönde etki yapacağı ve bunun sonucunda müşteri memnuniyetinin artacağı öngörülmektedir. Araştırma için kurulan model ile bu öngörü test edilecektir. Analizler sonucunda hem uygulayıcılar hem de araştırmacılara çeşitli öneriler getirilecektir.

\section{LITERATÜR ARAŞTIRMASI VE HIPOTEZLER}

$\mathrm{Bu}$ araştırma itibar, algılanan değer, memnuniyet ve ulaşılabilirlik kavramları arasındaki etki düzeylerini incelemek için tasarlanmıştır. $\mathrm{Bu}$ nedenle, literatür taraması bu kavramlar üzerinde yoğunlaşmıştır.

\section{I. Memnuniyet}

Rekabetin çok yoğun yaşandığı günümüzde işletmeler rekabet avantajı sağlamak için müşterilerini memnun etmek durumundadırlar. Müşteri memnuniyeti, tüketicinin alım sonrası elde ettikleri ile beklentilerini karşılaştırdığında ortaya çıkan olumlu durumdur (Peter \& Olson, 2010). Bir mal ya da hizmetle ilgili beklentileri karşılanmış bir müşterinin, işletmede tutulması ve tekrar mal ve hizmet satın almasının sağlanması, diğer kişilerin işletmeden mal ve hizmet almasından çok daha kolay olacaktır. Bağlı müşteriler, çevrelerindeki insanlara işletme hakkında olumlu tavsiyelerde bulunarak işletmenin adının duyulmasını ve tanınmasını sağlarlar (Çatı \& Koçoğlu, 2008). Müşteri memnuniyeti, firmaların uzun dönem rekabet avantajı sağlamalarında ve amaçlarına ulaşmalarında önemli bir rol üstlenmiştir (Henning-Thurau \& Klee, 1997). Schiffman ve Kanuk tüketici memnuniyetini, bireylerin mal ve hizmetten algıladıkları performans ile kendi beklentileri arasındaki ilişki olarak tanımlamaktadır. Yazarlara göre tüketici memnuniyeti kavramı tüketici 
beklentilerinin bir fonksiyonudur. Tüketicinin ürünle ilgili tecrübeleri beklentilerinden yüksek ise o tüketici memnun olmakta, düşük ise memnun olamamaktadır (Schiffman \& Kanuk, 2004'ten aktaran Tolon, 2007).

\section{II. Ulaşılabilirlik}

Hizmetlerin sunumunda müşteri ve servis sağlayıcının yüz yüze karşılaşma gerekliliği, coğrafi anlamda müşteri ile firmanın bir araya gelmesini gerektirmektedir. $\mathrm{Bu}$ durum hizmet sektöründe coğrafi yakınlığı ön plana çıkarmaktadır (Cho, 2006). Bunun yanında, müşteriler satın aldıkları hizmetlere daha kolay ulaşmayı istemektedirler (Devlin, 1995). İşletmelerin bu noktada yapacakları uygulamalarla müşterilerin hizmetlere daha kolay ulaşmalarını sağlamaları önem arz etmektedir. Bu açıdan bakıldığında, elektronik ticaret ve yeni teknolojilerin kullanılmaya başlaması işletmelerin işini kolaylaştırmıştır. Savaş ve Kesmez'in 2014 yılında yaptıkları çalışmada ulaşılabilirlik, "müşterinin hizmet kuruluşu ile ilişki kurma kolaylığı ve yakınlaşma ölçüsüdür” şeklinde tanımlanmıştır. Ghasemaghaei ve Hassanein’in (2015) online bilgi kalitesi üzerine yaptıkları bir başka çalışmada ulaşılabilirlik, aranan bilgilerin elde edilme kolaylığı olarak açıklanmıştır. Bugün birçok sektörde (perakende, turizm, eğitim, danışmanlık hizmetleri ve finansal hizmetler), gelişen teknolojiler ile birlikte, müşterilerin firmalara ve hizmetlere ulaşımını daha kolay hale getirmek için dijital uygulamalar kullanılmaktadır (Cho, 2006). Ulaşılabilirlik Parasuraman, Zeithaml ve Berry’nin $(1985,1988)$ geliştirdiği hizmet kalitesi modelinde kalitenin alt boyutu olarak görülmektedir. Bu çalışmada ise ulaş1labilirlik, kolay iletişim kurma, telefonla hizmetlere kolay ulaşma, bekleme süresinin uzun olmaması, hizmetin uygun saatlerde sunulması ve hizmetin sunum yerinin alanının uygun bir yerde olması şeklinde tanımlanmaktadır.

Ulaşılabilirlik kavramı ile hizmeti alan kişilerin memnuniyeti arasında pozitif bir ilişkinin olduğu çeşitli çalışmalarla tespit edilmiştir. Wu ve arkadaşlarının (2013) sağlık hizmetleri alanında yapmış olduğu çalışmada ulaşılabilirliğin memnuniyeti pozitif bir şekilde etkilediği tespit edilirken, sağlık hizmetleri alanında yapılan başka bir çalışmada (Lobo vd., 2014), ulaşılabilirliğin memnuniyet üzerinde oldukça düşük ve negatif bir etkisi bulunmuştur. Festival turizmi üzerine yapılan bir çalışmada ise (Pratiwi, Zhao, \& Mi, 2014) turist memnuniyetinin sunulan hizmetlere ulaşım (erişim) kolaylığı ile ilgili olduğu öne sürülmüştür.

$\mathrm{Bu}$ bilgilerden hareketle, bu çalışmada, otobüs firmalarının sunduğu hizmetlere kolay ulaşımın (şubeler, internet üzerinden sunulan hizmetler, otobüslere binme durakları vb.) müşteri memnuniyetini artıracağı düşüncesiyle aşağıdaki hipotez geliştirilmiştir. 
$\mathrm{H}_{1}$ :Otobüs firmalarının sundukları hizmetlere yönelik ulaşılabilirliğin müşteri memnuniyeti üzerinde anlamlı ve pozitif bir etkisi vardır.

Davies ve arkadaşları (2004) kurumsal itibarın oluşması için 7 başlık belirlemişlerdir. $\mathrm{Bu}$ başlıklardan birisi de sunulan hizmetlere müşterilerin çabuk ulaşmasını içeren ulaşılabilirlik kavramıdır. Benzer şekilde, Davies ve arkadaşlarının (2001) itibarın geliştirilmesi için ikinci düzeyde önemli gördükleri değişken ulaşılabilirliktir. Ayrıca Parasuraman, Zeithaml ve Berry’nin (1985) geliştirdiği hizmet kalitesi modelinde ulaşılabilirlik hizmet kalitesinin bir alt boyutu olarak görülmektedir. Dolayısı ile hizmet kalitesinin itibarı artırıcı yönde etkili olduğu söylenebilir. Bu noktadan hareketle aşağıdaki hipotez geliştirilmiştir.

$\mathrm{H}_{2}$ : Otobüs firmalarının sundukları hizmetlere yönelik ulaşılabilirliğin firma itibarı üzerinde anlamlı ve pozitif bir etkisi vardır.

Nugroho ve Suroto'nun 2015 yılındaki çalışmasında ulaşılabilirliğin artmasının müşterinin elde ettiği değeri de artıracağı öne sürülmüştür. Ayrıca, ulaşılabilirlik kavramının hizmet kalitesi ile ilişkili olmasından dolayı, birçok çalışmada (Vera \& Trujillo, 2013; Jiang, Jun, \& Yang, 2013; Mokhtaran, Fakharyan, Jalilvand, \& Mohebi, 2015; Zameer, Tara, Kausar, \& Mohsin, 2015) ortaya konan kalite ile değer arasındaki pozitif ilişkinin, ulaşılabilirlikle değer arasında da olabileceği ileri sürülebilir. Bu bilgiler ışığında aşağıdaki hipotez geliştirilmiştir.

$\mathrm{H}_{3}$ : Otobüs firmalarının sundukları hizmetlere yönelik ulaşılabilirliğin müşteri algılanan değeri üzerinde anlamlı ve pozitif bir etkisi vardır.

\section{III. Firma İtibarı}

Formbrun ve Shanley’e göre (1990), bir firmanın paydaşları (yatırımcılar, çalışanlar ve tüketiciler) ürün tercihi, kariyer seçimi ve yatırım yapma kararlarını firmanın itibarına dayalı olarak vermektedirler. Bir tanımda itibar, kurumun geçmiş performansına ilişkin duygusal ve bilişsel değerlendirmeler ve gelecekteki davranışları ile ilgili tahminler bütünü olarak ifade edilmiştir (Gümüş \& Öksüz, 2009). İtibar, kendiliğinden ortaya çıkan bir sonuç değil, yönetilerek geliştirilebilen bir değerdir. İtibarı yüksek olan kuruluşlar pazarlama faaliyetlerini rakiplerine göre daha az maliyetle yürütebilmekte, dağıtım kanalları ile pazarlıklarında daha iyi sonuçlar alabilmekte, yeni müşteri edinme veya eski müşterilere yeni ürünler sunmada daha başarılı olabilmekte ve rakiplerinden gelecek tehditlere karşı koyabilmek için müşterilerini kaybetmeksizin zaman kazanabilmektedir (Bozkurt, 2011). 
Firma itibarı, işletmeler için kritik öneme sahiptir. Çünkü itibar, işlem maliyetlerini azaltır, finansal çıktıları pozitif şekilde etkiler, tüketici güveni ve bağlılık gibi müşteri temelli değerlerde artış sağlar ve örgütsel başarıları gerçekleştirmede önemli bir faktördür (Walsh \& Beatty, 2007). Bunların yanı sıra, itibar müşteri memnuniyetini de olumlu etkilemektedir (Loureiro \& Kastenholz, 2011; Sengupta, Balaji, \& Krishnan, 2015; Seidi vd., 2015) Elektronik ticaret üzerine kültürler aras1 karşılaştırmanın yapıldığı bir araştırmada ise, Koreli müşterilerin algıladıkları firma itibarının memnuniyetleri üzerinde bir etkisi bulunurken, ABD’li müşterilerde bu etki saptanamamıştır (Kim \& Lee, 2009). Otobüs firmalarının sahip oldukları itibar ile müşteri memnuniyeti arasındaki pozitif ilişki bu çalışmanın varsayımları arasındadır. $\mathrm{Bu}$ varsayımdan hareketle, aşağıdaki hipotez oluşturulmuşstur.

$\mathrm{H}_{4}$ : Otobüs firmalarının sahip olduğu itibar müşteri memnuniyetini anlamlı ve pozitif bir şekilde etkilemektedir.

\section{IV. Algılanan Değer}

Rekabette avantaj sağlamak isteyen işletmeler tüketiciye daha fazla değer sunmak durumundadırlar. Değer, tüketicilerin mal veya hizmet satın almadan önce veya aldıktan sonra işletmeye verdikleri ile karşılığında aldıklarını değerlendirmesi sonucu ortaya çıkmaktadır. Tüketicilerin satın aldığı ürüne karşı verdikleri (tüketici maliyeti); ödediği fiyat, zaman, çaba ve enerji şeklinde sıralanabilir (Zeithaml, 1988). Ayrıca, algılanan değer müşteri değerini etkileyen ana faktör olarak ifade edilmektedir (Bolton \& Drew, 1991). Bu noktadan hareketle aşağıdaki hipotez geliştirilmiştir.

$\mathrm{H}_{5}$ : Otobüs işletmelerinin sundukları hizmete yönelik algılanan tüketici değeri müşteri memnuniyetini anlamlı ve pozitif bir şekilde etkilemektedir.

\section{YÖNTEM}

Araştırmanın ana kitlesi Balıkesir Üniversitesi’nin Edremit Körfezi’nde yer alan meslek yüksekokullarında öğrenim gören ve başka bir şehirde yaşadığı için şehirlerarası otobüs işletmelerini kullanmak durumunda olan öğrencilerden oluşmaktadır. Balıkesir Üniversitesi’nin 2014-2015 Eğitim-Öğretim yılı Faaliyet Raporuna göre bu meslek yüksekokullarında toplam 4823 kayıtlı öğrenci bulunmaktadır. Ancak, bu öğrencilerin bir kısmı okula devam etmemekte, bir kısmı ise zaten Balıkesir ilinde ikamet ettiği için şehirlerarası otobüs işletmelerini kullanmamaktadır. Yüksekokullardan alınan bilgiler 1şığında, bu öğrencilerin yaklaşık 3500'ünün araştırmanın ana kitlesine dâhil olabileceği görülmüş̦ür. Bu noktadan hareketle, ilgili meslek yüksekokullarında 
kolayda örnekleme yöntemi ile belirlenmiş 375 öğrenci ile yüz yüze anket uygulaması yapılmıştır. Yapılan analizler sonucunda 20 anket eksik ya da yanlış doldurulduğu için araştırmaya dâhil edilmemiştir. Böylelikle analizlerde 355 ankete ilişkin veriler kullanılmıştır.

Araştırmanın anket formu iki bölümden oluşmaktadır. Birinci bölümde cevaplayıcıların demografik yapısını belirlemeye yönelik sorular yer almaktadır. İkinci bölümde ise araştırma değişkenlerini ölçmeye ilişkin ifadeler bulunmaktadır. Araştırmada kullanılan ölçekler 5'li Likert tipi ölçeğe göre düzenlenmiştir (1-Kesinlikle katılmıyorum, 2- Katılmıyorum, 3- Ne Katılıyorum Ne Katılmiyorum, 4- Kat1lıyorum, 5- Kesinlikle Kat1lıyorum).

Müşteri memnuniyeti ölçeği, Swaen ve Chumpitaz'ın 2008'deki çalışmasından alınmıştır. Firma itibarı, Casalo, Flavian ve Guinaliu'nun 2007'deki çalışmasından alınan 4 soru ve firmanın toplumdaki genel durumunu gösteren bir soru kullanılarak ölçülmüştür. Algılanan değer ölçeği Grewal, Monroe ve Krishnan'ın 1998'deki çalışmasında geliştirdikleri 4 soru ve Turan ve Çolakoğlu'nun 2009 yılındaki çalışmalarından alınan 1 soru ile toplam 5 yargı kullanılarak ölçülmeye çalışılmıştır. Ulaşılabilirlik ölçeği ise Van Dun, Bloemer ve Henseler'in çalışmasından (2010) 2 soru, Yang ve arkadaşlarının 2005’teki çalışmasından 2 soru ve Bahia ve Nantel'in (2000) çalışmasından alınan 2 soru bir araya getirilerek toplam 6 soru ile ölçülmüştür.

Verilerin analizinde, güvenilirlik analizleri, açıklayıcı ve doğrulayıcı faktör analizleri, tanımlayıcı istatistikler ve korelâsyon analizleri kullanılmıştır. Bu analizlerde SPSS 20.0 paket programı kullanılmıştır. Hipotezlerin testinde, kurgulanan yapısal eşitlik modellemesi AMOS 16 programı ile analiz edilmiştir.

\section{I. Araștırmanın Amacı}

$\mathrm{Bu}$ araştırmanın amacı, Balıkesir Üniversitesi'nin Edremit Körfezi’ndeki meslek yüksekokullarında (Edremit Meslek Yüksekokulu, Havran Meslek Yüksekokulu, Ayvalık Meslek Yüksekokulu, Altınoluk Meslek Yüksekokulu ve Burhaniye Meslek Yüksekokulu) öğrenim gören öğrencilerin kullandıkları şehirlerarası otobüs firmalarının ulaşılabilirliğine yönelik algılarının firma itibarı, algılanan değer ve memnuniyet üzerindeki etkilerini ölçmektir. Bu bağlamda oluşturulan modeli Şekil I'de görülmektedir. 


\section{II. Araştırmanın Modeli ve Hipotezleri}

Şekil I’de gösterilen araştırma modeline göre bir firmanın ulaşılabilir olmasının (hizmetin sunulduğu mekâna ulaşım ya da web sitesi, telefon gibi araçlarla firmaya kolay ulaşabilme), müşterinin algıladığı firma itibarı, müşteri memnuniyeti ve müşterinin firmadan algıladı̆̆ değer üzerinde olumlu yönde bir etki yapacağı varsayılmaktadır. Ayrıca, müşterinin algıladığı firma itibarının ve algıladığg değerin yüksek olması durumunda müşteri memnuniyetinin de yükseleceği düşünülmektedir. Araştırma modeli bu temel varsayımlar üzerine kurgulanmıştır.

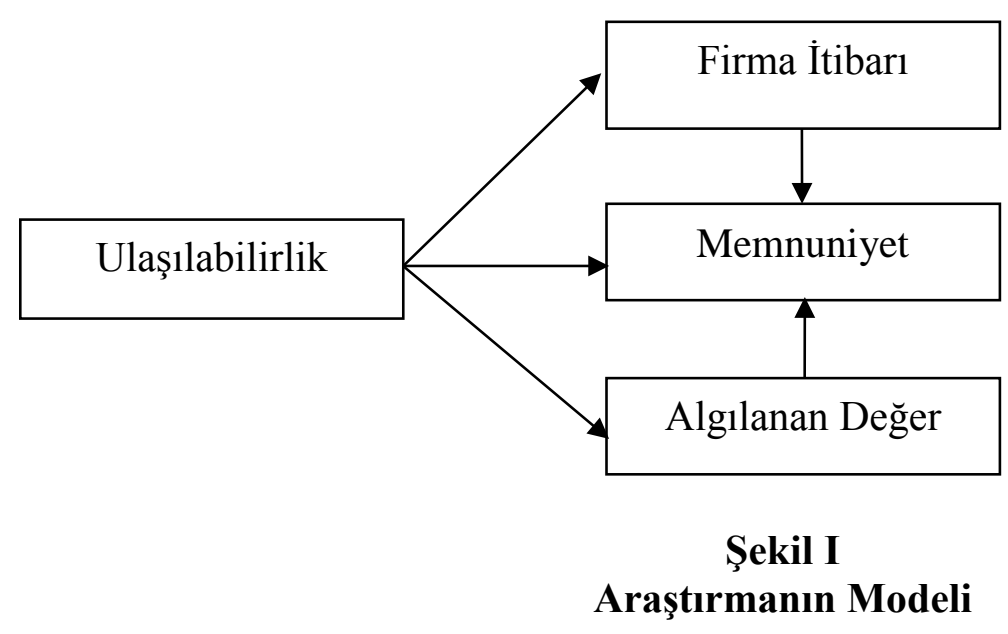

\section{ARAŞTIRMANIN BULGULARI}

\section{IV.I. Demografik Bulgular}

Araştırmaya katılanların \%37,5'i kadın, \%62,5 i erkektir. Araştırmaya katılan öğrencilerin \%29'u 0-1000 aras1, \%28,6's1 1001-1500 arası, \% 21,2'si 1501-2000 aras1 ve \%21,2'si 2000 ve üzeri aylık gelire sahip olduğunu ifade etmiştir. Çalışmaya katılan öğrencilerin, \%13,3'ü Altınoluk MYO, \%24,4’ü Ayvalık MYO, \%24'ü Burhaniye MYO, \%23'ü Edremit MYO ve \%14,4'ü Havran MYO da eğitim görmektedir. Öğrencilerin \%26,3'ü pazarlama, \%16,9'u mekatronik, \%14,4'ü işletme, \% 8,6'sı turizm işletmeciliği ve otelcilik, \%7,8'i bilgisayar, \%7,8'i muhasebe, \%5'i kimya, \%4,4'ü büro yönetimi, \%2,5'i makine, \%2,2'si mimari dekorasyon, \%2,2'si tıbbi ve aromatik bitkiler bölümlerinde öğrenim gördüğünü ifade etmiştir.

Tablo I'de araştırmaya katılan öğrencilerin Edremit Körfezi’ndeki meslek yüksekokullarına öğrenim görmek için geldikleri şehirler ve kullandıkları otobüs işletmeleri görülmektedir. Buna göre, araştırmaya katılan öğrenciler Edremit Körfezi'ne 41 farklı şehirden gelmekte ve yoğunluklu 
olarak geldikleri şehirler İstanbul, Bursa, İzmir, Manisa ve Çanakkale olarak sıralanmaktadır. Araştırmaya katılan öğrenciler Edremit Körfezi'ne geliş gidişlerinde 28 farklı otobüs işletmesini tercih etmekte ve öğrencilerin en çok tercih ettikleri otobüs işletmeleri ise Kamil Koç, Metro, Truva, Anadolu ve Ulusoy olarak siralanmaktadır.

Tablo I

Frekans Analizi

\begin{tabular}{|c|c|c|c|c|c|c|c|}
\hline $\begin{array}{l}\text { Geldiği } \\
\text { Yer }\end{array}$ & $\%$ & Geldiği Yer & $\%$ & $\begin{array}{l}\text { Kullandığı } \\
\text { Firma }\end{array}$ & $\%$ & $\begin{array}{l}\text { Kullandığı } \\
\text { Firma }\end{array}$ & $\%$ \\
\hline Adana & 0,6 & Kayseri & 1,7 & Anadolu & $\% 6,4$ & Nilüfer & $\% 0,6$ \\
\hline Afyon & 0,6 & Kırklareli & 0,6 & Astur & $\% 0,6$ & Özbolu & $\% 0,3$ \\
\hline Amasya & 0,3 & Kirşehir & 0,3 & Balıkesir & $\% 0,6$ & Pamukkale & $\% 3,9$ \\
\hline Ankara & 3,6 & Kocaeli & 1,7 & Baltur & $\% 0,3$ & Sarık1z & $\% 0,6$ \\
\hline Antalya & 0,8 & Kütahya & 0,8 & Bayburt & $\% 0,3$ & Sebat & $\% 3$ \\
\hline Aydin & 0,6 & Manisa & 5,3 & Bayramiç & $\% 1,1$ & Seç & $\% 0,8$ \\
\hline Bayburt & 0,3 & Mersin & 1,1 & Cizre Nuh & $\% 0,3$ & Soma & $\% 1,1$ \\
\hline Bitlis & 0,3 & Muğla & 0,8 & Düzce Güven & $\% 0,3$ & Süha & $\% 0,8$ \\
\hline Bolu & 1,1 & Ordu & 0,3 & Efe Tur & $\% 2,5$ & Tatlises & $\% 0,6$ \\
\hline Bursa & 20,5 & Rize & 0,3 & Kamberoğlu & $\% 0,3$ & Topçam & $\% 0,3$ \\
\hline Çanakkale & 3,3 & Samsun & 0,3 & Kamil Koç & $\% 31,3$ & Truva & $\% 6,9$ \\
\hline Çorum & 0,8 & Şrnak & 0,3 & Kontur & $\% 0,3$ & Uludağ & $\% 3,3$ \\
\hline Düzce & 0,6 & Sinop & 0,3 & Manisa & $\% 0,3$ & Ulusoy & $\% 5,8$ \\
\hline Edirne & 0,6 & Sivas & 0,8 & Metro & $\% 24,1$ & Varan & $\% 1,7$ \\
\hline Erzincan & 0,3 & Tekirdağ & 1,9 & & & & \\
\hline Erzurum & 0,3 & Tokat & 1,1 & & & & \\
\hline Eskişehir & 0,6 & Trabzon & 1,4 & & & & \\
\hline Hakkâri & 0,3 & Urfa & 0,8 & & & & \\
\hline İstanbul & 32,1 & Yalova & 0,6 & & & & \\
\hline İzmir & 9,4 & Zonguldak & 0,8 & & & & \\
\hline Kars & 0,3 & & & & & & \\
\hline
\end{tabular}

\section{II. Faktör Analizi}

Çalışmada kullanılan değişkenlerin faktör yapılarını ve ölçek güvenilirliklerini belirlemek amacıyla açıklayıcı faktör analizi (AFA) ve doğrulayıcı faktör analizi (DFA) yapılmıştır. Açıklayıcı faktör analizi sonuçları Tablo II'de görülmektedir. 


\section{Tablo II}

Açıklayıcı Faktör Analizi

\begin{tabular}{|c|c|c|c|c|}
\hline & $\begin{array}{l}\text { Faktör } \\
\text { Yükleri }\end{array}$ & Özdeğer & $\begin{array}{c}\text { Açılananan } \\
\text { Varyans }\end{array}$ & $\begin{array}{c}\text { Cronbach'ın } \\
\text { Alfa Katsayısı }\end{array}$ \\
\hline \multicolumn{5}{|c|}{ Memnuniyet } \\
\hline m3 & 0,807 & \multirow{6}{*}{8,137} & \multirow{6}{*}{40,685} & \multirow{6}{*}{0,853} \\
\hline m7 & 0,757 & & & \\
\hline m6 & 0,718 & & & \\
\hline m5 & 0,601 & & & \\
\hline m2 & 0,565 & & & \\
\hline m4 & 0,558 & & & \\
\hline \multicolumn{5}{|c|}{ Ulaşılabilirlik } \\
\hline u1 & 0,773 & \multirow{5}{*}{1,537} & \multirow{5}{*}{7,685} & \multirow{5}{*}{0,816} \\
\hline u3 & 0,757 & & & \\
\hline u2 & 0,701 & & & \\
\hline u4 & 0,614 & & & \\
\hline u5 & 0,544 & & & \\
\hline \multicolumn{5}{|c|}{ Firma İtibarı } \\
\hline i3 & 0,759 & \multirow{5}{*}{1,076} & \multirow{5}{*}{5,832} & \multirow{5}{*}{0,808} \\
\hline i1 & 0,724 & & & \\
\hline $\mathrm{i} 2$ & 0,700 & & & \\
\hline i5 & 0,540 & & & \\
\hline $\mathrm{i} 4$ & 0,508 & & & \\
\hline \multicolumn{5}{|c|}{ Algılanan Değer } \\
\hline ad3 & 0,766 & \multirow{4}{*}{1,007} & \multirow{4}{*}{5,037} & \multirow{4}{*}{0,605} \\
\hline ad4 & 0,592 & & & \\
\hline ad2 & 0,587 & & & \\
\hline ad1 & 0,426 & & & \\
\hline $\begin{array}{l}\text { Çık } \\
\text { DöI } \\
\text { Aç1 }\end{array}$ & $\begin{array}{l}\text { emel Bile } \\
\text { Varimax } \\
\text { Varyans: }\end{array}$ & $\begin{array}{l}\text { er Analizi. } \\
, 239\end{array}$ & & \\
\hline
\end{tabular}

Araştırmada faktör analizinin yapılabilmesi için gerekli olan KMO (Kaiser-Meyer-Olkin) örneklem yeterlilik katsayısı 0,932 ve evren korelâsyon matrisinin birim matris olmadığını gösteren Bartlett küresellik testinin p değeri 0,001 olarak hesaplanmıştır. Bu sonuçlar örnek büyüklüğünün yeterli olduğunu ve verilerin faktör analizi için uygun olduğunu göstermektedir. AFA sonucunda, algılanan değer, memnuniyet ve ulaşılabilirlik boyutlarından M1, U6 ve AD5 soruları faktör yükleri düşük olduğu ya da faktör yapısını bozduğu için araştırma kapsamından çıkarılmıştır. Ortaya çıkan yapının açıklanan varyans değeri 59,239’dur.

AFA sonucunda ortaya çıkan faktör yapılarının doğruluğunu tespit etmek için AMOS 16 paket programı kullanılarak DFA yapılmıştır. Tablo III’te DFA sonuçları görülmektedir. 


\section{Tablo III}

Doğrulayıcı Faktör Analizi Sonuçları

\begin{tabular}{lcc}
\hline $\begin{array}{c}\text { Araştırmada Kullanılan Sorular ve } \\
\text { ilişkili oldukları değişkenler }\end{array}$ & $\begin{array}{c}\text { Standardize } \\
\text { Faktör Yükleri }\end{array}$ & CR \\
\hline m6 <---Memnuniyet & 0,671 & \\
m5 <---Memnuniyet & 0,711 & \\
m4 <---Memnuniyet & 0,729 & 0,853 \\
m3 <---Memnuniyet & 0,658 & \\
m7 <---Memnuniyet & 0,642 & \\
m2 <---Memnuniyet & 0,751 & \\
i5 <---İtibar & 0,674 & \\
i4 <---İtibar & 0,654 & \\
i3 <---İtibar & 0,758 & \\
i2 <---İtibar & 0,661 & \\
i1 <---İtibar & 0,648 & \\
u5 <---Ulaş1labilirlik & 0,693 & \\
u4 <---Ulaş1labilirlik & 0,657 & \\
u3 <---Ulaş1labilirlik & 0,703 & \\
u2 <---Ulaş1labilirlik & 0,703 & \\
u1 <---Ulaş1labilirlik & 0,678 & \\
ad4 <---Alg1lanan Değer & 0,690 & \\
ad2 <---Algılanan Değer & 0,806 & \\
ad1 <---Algılanan Değer & 0,709 & \\
\hline & &
\end{tabular}

Hair ve arkadaşlarına göre, iyi bir yapı için Composite Reliability (CR) katsayısının 0,70 ve üzeri olması gerekir. Ayrıca, faktör yükleri için 0,70 eşiği önemli bir eşik olarak değerlendirilirken 0,50 ve altı değerlerin uygun olmadığı belirtilmektedir (Hair, Lukas, Roberts, \& Lee-Lukas, 2014). Tablo 3'te görüldüğü gibi, tüm boyutlar için CR değerleri 0,70'in üzerindedir. Faktör yükleri açısından sonuçlar değerlendirildiğinde ise ideal yapının üzerinde ya da ideal yapıya yakın değerlerin ortaya çıktığı görülmektedir.

Tablo IV

DFA Model Uyum Değerleri

\begin{tabular}{lccc}
\hline \multicolumn{1}{c}{ Uyum Ölçütü } & İyi Uyum & $\begin{array}{c}\text { Kabul Edilebilir } \\
\text { Uyum }\end{array}$ & Model Uyum Değerleri \\
\hline CMIN/DF $\left(X^{2} / \mathrm{df}\right)$ & $0 \leq X^{2} / \mathrm{df} \leq 2$ & $2<X^{2} / \mathrm{df} \leq 3$ & 2,271 \\
RMSEA & $0 \leq \mathrm{RMSEA} \leq 0,05$ & $0,05<\mathrm{RMSEA} \leq 0,08$ & 0,060 \\
SRMR & $0 \leq \mathrm{SRMR} \leq 0,05$ & $0,05<\mathrm{SRMR}<0,10$ & 0,049 \\
CFI & $0,97 \leq C F I \leq 1,00$ & $0,95 \leq C F I<0,97$ & 0,937 \\
GFI & $0,95 \leq G F I \leq 1,00$ & $0,90 \leq \mathrm{GFI}<0,95$ & 0,914 \\
\hline
\end{tabular}

Kaynak: Schermelleh-Engel ve Moosbrugger (2003)

DFA sonucunda ortaya çıkan model uyum değerleri ve eşik değerler Tablo IV'te sunulmuştur. Buna göre, DFA sonucunda ortaya çıkan model değerlerinin çoğu $\left(X^{2} / \mathrm{df}, \mathrm{RMSEA}\right.$, SRMR ve GFI) kabul edilebilir uyum değerlerine sahipken, CFI'nın kabul edilebilir değerin biraz altında kaldığı görülmektedir. 


\section{III. Ölçeklere İlişkin Tanımlayıcı İstatistikler}

Tablo V’te ölçeklere ilişkin ortalama ve standart sapma değerleri ile korelâsyon katsayıları sunulmuştur. Buna göre, değişkenler arasında yüksek korelâsyonlar olduğu söylenebilir. Ayrıca tüm değişkenlere ilişkin aritmetik ortalama değerleri ortalamanın üzerinde yer almaktadır. Bu sonuçlar, cevaplayıcıların otobüs işletmelerinden memnuniyet düzeylerinin (3,593), müşterisi olduğu firmanın itibarı hakkındaki düşüncelerinin (3,962), firma hizmetlerinin ulaşılabilir olması hakkındaki görüşlerinin $(3,888)$ ve firmadan algıladıkları değerin $(3,750)$ ortalamanın üzerinde olduğunu göstermektedir. Ancak burada en düşük ortalama değerin memnuniyet değişkenine ait olduğu da gözden kaçırılmaması gereken bir sonuçtur.

\section{Tablo V}

Ölçeklere İlişkin Tanımlayıcı İstatistikler ve Korelâsyon Katsayıları

\begin{tabular}{lccccc}
\hline & \multicolumn{3}{c}{$\begin{array}{c}\text { Korelâsyon } \\
\text { Katsayıları }\end{array}$} & Ortalama & Standart sapma \\
\cline { 2 - 4 } FAKTÖRLER & $(1)$ & $(2)$ & $(3)$ & & 0,881 \\
\hline (1) Memnuniyet & & & 3,593 & 0,746 \\
(2) İtibar & 0,617 & & 3,962 & 0,786 \\
(3) Ulaş1labilirlik & 0,569 & 0,640 & 3,888 & 0,831 \\
(4) Algılanan Değer & 0,654 & 0,647 & 0,603 & 3,750 & \\
\hline
\end{tabular}

\section{IV. Hipotezlerin Testi}

Araştırma hipotezlerinin testi, AMOS 16 paket programı kullanılarak yapısal eşitlik modellemesi şeklinde yapılmıştır. Araştırma modelinin program çıktısı Şekil II'de görülmektedir. 


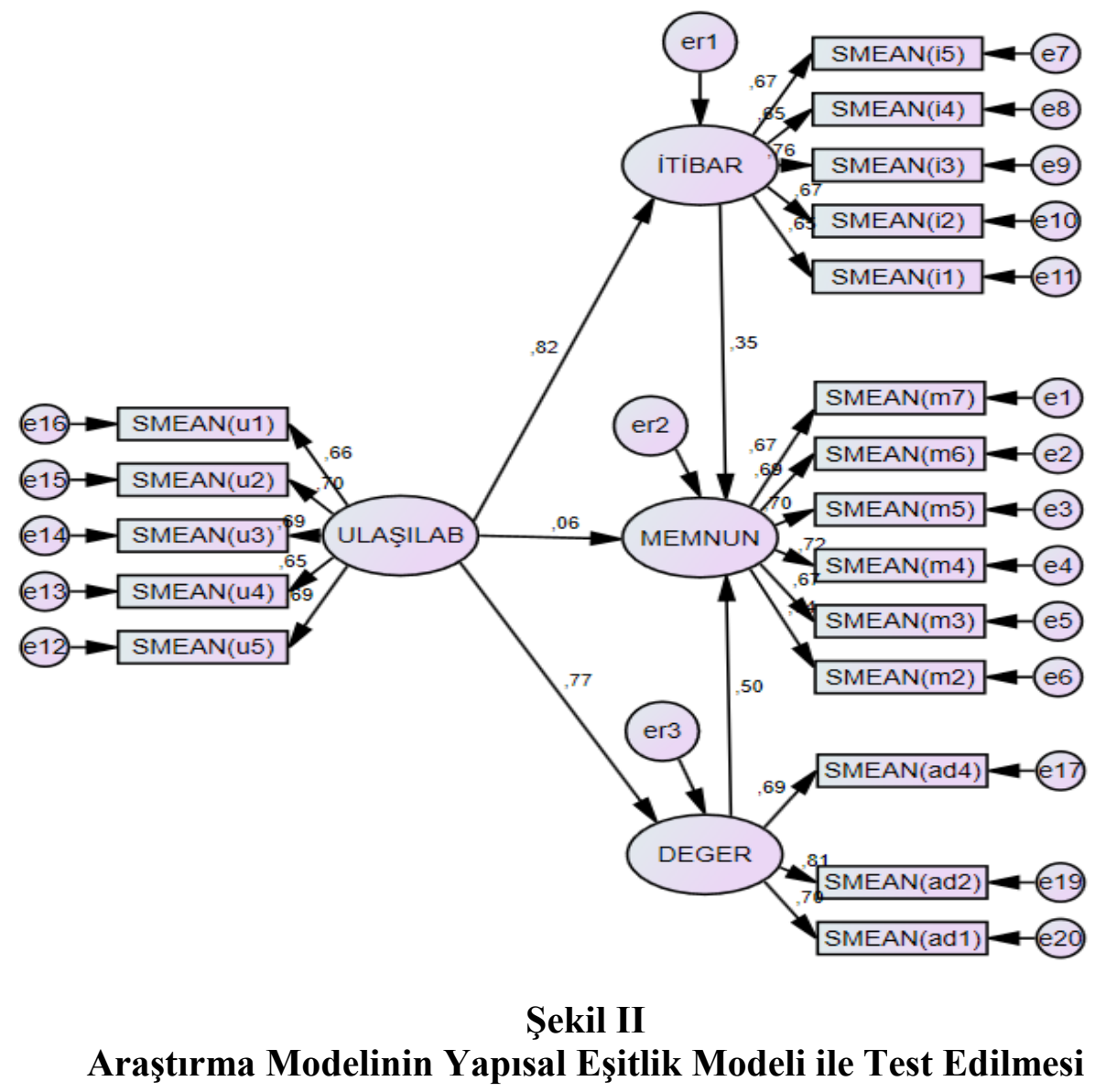

Şekil II'de görülen araştırma modelinin yapısal eşitlik modeli analiz sonuçları yüzeysel olarak incelendiğinde, ulaşılabilirlik değişkeninin memnuniyet üzerindeki etkisinin standardize edilmiş $\beta$ değerinin oldukça düşük kaldığı; öte yandan diğer tüm yollara ilişkin standardize edilmiş $\beta$ değerlerinin görece yüksek olduğu gözlenmektedir. Bu yolların anlamlı olup olmadığı Tablo VI'da gösterilmiştir.

Tablo VI

Yapısal Eşitlik Modellemesi Yol Analizi Sonuçları

\begin{tabular}{ccccc}
\hline Değişkenler Arası İlişkiler & $\begin{array}{c}\text { Standardize } \\
\text { Edilmiş } \boldsymbol{\beta}\end{array}$ & $\mathbf{t}$ & $\mathbf{p}$ \\
\hline MEMNUN <--- ULAŞILAB & 0,059 & 0,429 & 0,668 \\
ITIBAR $<---$ ULAŞILAB & 0,818 & 9,916 & 0,001 \\
DEGER $<---$ ULAŞILAB & 0,767 & 9,588 & 0,001 \\
MEMNUN <--- İTIBAR & 0,354 & 3,313 & 0,001 \\
MEMNUN <--- & DEGER & 0,503 & 5,049 & 0,001 \\
\hline
\end{tabular}


Tablo VI'da yer alan bulgular, ulaşılabilirlik değişkeninin itibar $(\beta=0,818)$ ve algilanan değer $(\beta=0,767)$ üzerinde güçlü bir etkiye sahip olduğunu ve bu etkinin pozitif (sırasıly $\mathrm{t}=9,916$ ve 9,588) ve anlamlı (her ikisi için $\mathrm{p}=0,001$ düzeyinde) olduğunu göstermektedir. $\mathrm{Bu}$ sonuçlara ek olarak, itibar $(\beta=0,354)$ ve algılanan değer $(\beta=0,503)$ değişkenlerinin de memnuniyet üzerinde pozitif (sırasıyla $t=3,313$ ve 5,049 ) ve anlamlı (her ikisi için $p=0,001$ düzeyinde) bir etkisi tespit edilmiştir. Diğer taraftan, ulaşılabilirlik değişkeninin memnuniyet üzerinde olması beklenen etkisi, araştırma sonucuna göre tespit edilememiştir $(\beta=0,354 ; \mathrm{t}=0,429 ; \mathrm{p}=0,668)$. Bu sonuçlara göre $\mathrm{H} 1$ hipotezi reddedilirken, $\mathrm{H} 2, \mathrm{H} 3, \mathrm{H} 4$ ve $\mathrm{H} 5$ hipotezleri kabul edilmiştir.

Tablo VII

Yapısal Eşitlik Modeli Uyum Değerleri

\begin{tabular}{lccc}
\hline \multicolumn{1}{c}{ Uyum Ölçütü } & İyi Uyum & $\begin{array}{c}\text { Kabul Edilebilir } \\
\text { Uyum }\end{array}$ & Model Uyum Değerleri \\
\hline CMIN/DF $\left(X^{2} / \mathrm{df}\right)$ & $0 \leq X^{2} / \mathrm{df} \leq 2$ & $2<X^{2} / \mathrm{df} \leq 3$ & 2,460 \\
RMSEA & $0 \leq \mathrm{RMSEA} \leq 0,05$ & $0,05<\mathrm{RMSEA} \leq 0,08$ & 0,064 \\
SRMR & $0 \leq \mathrm{SRMR} \leq 0,05$ & $0,05<\mathrm{SRMR}<0,10$ & 0,0527 \\
CFI & $0,97 \leq C F I \leq 1,00$ & $0,95 \leq C F I<0,97$ & 0,926 \\
GFI & $0,95 \leq G F I \leq 1,00$ & $0,90 \leq \mathrm{GFI}<0,95$ & 0,906 \\
\hline
\end{tabular}

Kaynak: Schermelleh-Engel ve Moosbrugger (2003)

Yapısal eşitlik modellemesi sonucunda ortaya çıkan model uyum değerleri ve eşik değerler Tablo VII'de sunulmuştur. Buna göre, yapısal modelin analizi sonucunda ortaya çıkan değerlerin çoğu (X²/df, RMSEA, SRMR ve GFI) kabul edilebilir uyum değerlerine sahipken, CFI'nın kabul edilebilir değerin biraz altında kaldığı görülmektedir. Bu değerlerden hareketle araştırma modelinin bütün halinde kabul edilebilir düzeyde bir uyum gösterdiği söylenebilir. Bu bulgular, araştırma modelinde yer alan hipotezlerin analiz sonuçlarının doğruluğu konusunda önemli birer kanıt niteliğindedir.

\section{SONUÇ VE ÖNERILER}

Hizmet pazarlamasına ilişkin literatür incelendiğinde, müşteri memnuniyetine yönelik araştırmaların genellikle hizmet kalitesi ile memnuniyet arasındaki ilişkiye odaklandığı görülmektedir (Sivadas \& Baker-Prewitt, 2000; Olorunniwo, Hsu, \& Udo, 2006; Kuo, Wu, \& Deng, 2009). Hizmet kalitesinin ulaşılabilirlik boyutunun doğrudan müşteri memnuniyetine etkisi üzerine yapılmış az sayıda araştırma bulunmaktadır. Literatür taraması bölümünde de ifade edildiği gibi, bu çalışmalarda genellikle beklenen pozitif etkinin saptandığı görülmektedir. $\mathrm{Bu}$ araştırmanın en önemli sonucu, beklenmeyen bir biçimde bu etkinin saptanamamış olmasıdır. Bunun nedeni olarak, müşterilerin gelişen teknoloji ve şube ağıyla birlikte otobüs işletmelerinin hizmetlerine kolay ulaşabildiği ve bunun zaten firmanın yapması gereken bir hizmet olduğunu düşündüğü için de memnuniyetinin artmadığı görülebilir. 
Araştırmada ortaya çıkan başka bir sonuç ise, müşterinin kullandığı otobüs işletmesine ulaşılabilirliğin firma itibarı üzerinde pozitif bir etkisi olduğudur. Literatür taraması bölümünde de değinildiği gibi, tüketiciler ürün tercihini yaparken firmanın itibarından etkilenmektedir. Ulaşılabilirlik ise hizmet kalitesinin önemli unsurlarından biridir. Bu nedenle, ulaşılabilir hizmetler sunan bir işletmenin müşteriler gözündeki itibarının da artması beklenen bir sonuçtur.

Çalışmanın bir diğer sonucu, müşterinin kullandığı otobüs işletmesine ulaşılabilirliğin müşteri algılanan değeri üzerinde pozitif bir etkisi olduğudur. Nugroho ve Suroto (2015) da araştırmasında benzer bir sonuca ulaşmıştır. $\mathrm{Bu}$ sonuçtan hareketle, otobüs işletmesinin hizmetlerinin ulaşılabilir olmasının müşterinin firmadan algıladığı değeri artıracağı söylenebilir.

Müşterilerin otobüs işletmelerinden algıladıkları değerin memnuniyet üzerindeki pozitif etkisinin saptanmış olması, bu araştırmanın ortaya koyduğu diğer bir sonuçtur. Bu araştırmayla benzer bir şekilde, Tayvan'da hava yolu müşterileri üzerinde yapılan bir araştırmada algılanan değerin müşteri memnuniyetini pozitif bir biçimde etkilediği bulunmuştur (Chen, 2008). Ayrıca, hizmet sektörünün farklı alt sektörlerinde yürütülmüş olan çeşitli çalışmalarda da bu etki saptanmıştır (Kuo, Wu, \& Deng, 2006; Hu, Kandampully, \& Juwaheer, 2009; Ryu, Lee, \& Kim, 2012; Wu, 2014; Jo, Lee, \& Reisinger, 2014; Chung, Yu, \& Shin, 2015). Bu sonuçtan hareketle, otobüs işletmelerinin müşteri gözündeki değeri arttıkça müşterinin işletmeden memnuniyet düzeyinin de artacağı söylenebilir.

Araştırmadan elde edilen bir başka sonuç, müşterilerin kullandıkları otobüs işletmesinin itibarının müşteri memnuniyetini pozitif yönde etkilediğidir. Literatürde iyi bir firma itibarının müşteri memnuniyetine neden olacağına ilişkin benzer araştırma sonuçları bulunmaktadır. Davies ve arkadaşları (2002), perakende sektöründe firma itibarının müşteri memnuniyeti üzerinde pozitif bir etkisi olduğunu ortaya koymuştur. Bir başka çalışmada ise, müşterilerin firmadan algıladıkları itibar ile müşteri memnuniyeti arasında oldukça yüksek bir pozitif korelâsyon $(0,85)$ tespit edilmiştir (Walsh, Dinnie, \& Wiedmann, 2006).

Araştırma sonuçlarına göre, otobüs işletmeciği sektöründe faaliyet gösteren fïrmalara, müşteri memnuniyetini artırmak için faaliyetlerinde ulaşılabilir olmaya özen göstermeleri, firma itibarını ve tüketicinin algıladığı değeri artıracak önlemler almaları önerisinde bulunulabilir. Bu önlemler müşteri memnuniyetini olumlu yönde etkileyecektir. Alınan önlemlerle geliştirilen ulaşılabilirlik özelliğine firma reklamlarında vurgu yapılarak, mevcut ve yeni müşteriler gözündeki firma itibarı ve değeri artırılabilecektir. Artan itibar ve değerin müşteri memnuniyetini olumlu yönde etkileyebileceği ve böylelikle firmaya bağlı müşteriler oluşturulabileceği unutulmamalıdır. 
$\mathrm{Bu}$ araştırma, kolayda örnekleme yöntemi ile belirlenen üniversite öğrencileri üzerinde gerçekleştirilmiştir. Her ne kadar, alan yazında ulaşılan çalışmaların çoğu bu örnekleme yöntemini kullanmış olsa da tesadüfî örnekleme yöntemlerinden birinin kullanılması sonuçların genellenebilirliği bakımından önemlidir. Ayrıca, üniversite öğrencileri üzerinde yapılan çalışmaların çeşitli yanlılık sorunlarını da beraberinde getirdiği bilinmektedir. Ancak, üniversite öğreniminden dolayı şehirlerarası otobüs işletmelerini sıklıkla kullandığ öğrencilerinin ana kitle olarak belirlenmesinin bu araştırma özelinde doğru olacağı düşünülmüştür. Bununla birlikte, farklı kitleler üzerinde yapılacak araştırmalarla, bu araştırmada ortaya çıkan bulguların geçerliliği için yeni kanıtlar ortaya konabilir. 


\section{REFERANSLAR}

Bahia, K. \& Nantel, J. 2000. A reliable and valid measurement scale for the perceived service quality of banks. International Journal of Bank Marketing, 18(2): 84-91.

Bolton, R.N. \& Drew, J. 1991. A longitudinal analysis of the impact of service changes on customer attitudes. Journal of Marketing, 55(1): 1-10.

Bozkurt, M. 2011. İşletmelerin itibar yönetimi faaliyetlerinin müşteri tutum ve tercihleri üzerindeki yansımaları. Uşak Üniversitesi Sosyal Bilimler Dergisi, 4(1): 150-168.

Casalo, V.L., Flavian, C., \& Guinaliu, M. 2007. The role of security, privacy, usability and reputation in the development of online banking. Online Information Review, 31(5): 583603.

Chen, C. 2008. Investigating structural relationships between service quality, perceived value, satisfaction, and behavioral intentions for air passengers: Evidence from Taiwan. Transportation Research Part A, 42: 709-717.

Cho, S-E. 2006. Factors affecting customer needs of geographical accessibility in electronic commerce. Electronic Commerce Research and Applications, 5: 131-139.

Chung, K.H., Yu, J.E., \& Shin, J.L. 2015. The relationship among perceived value, brand image, customer satisfaction, and customer loyalty: The moderating effect of gender. Proceedings of the 3rd International Congress on Interdisciplinary Behavior and Social Sciences, 145148.

Churchill, G.A. \& Surprenant, C. 1982. An investigation into the determinants of customer satisfaction. Journal of Marketing Research, 19(4): 491-504.

Çat1, K. \& Koçoğlu, M.C. 2008. Müşteri sadakati ile müşteri tatmini arasındaki ilişkiyi belirlemeye yönelik bir araştırma. Selçuk Üniversitesi Sosyal Bilimler Enstitüsü Dergisi, 19: 167-189.

Davies, G., Rosa, C., Silva Rui, V., \& Stuart, R. 2001. The personification metaphor as a measurement approach for corporate reputation, Corporate Reputation Review, 4(2): 113127. 
Davies, G., Rosa, C., Silva Rui, V., \& Stuart, R. 2004. A corporate character scale to assess employee and customer views of organization reputation. Corporate Reputation Review, 7(2): 125-146.

Devlin, J.F. 1995. Technology and innovation in retail banking distribution. The International Journal of Bank Marketing, 13: 19-25.

Fombrun, C. \& Shanley, M. 1990. What's in a name? Reputation building and corporate strategy. Academy of Management Journal, 33(2): 233-258.

Ghasemaghaei, M. \& Hassanein, H. 2015. Online information quality and consumer satisfaction: The moderating roles of contextual factors - A meta-analysis. Information \& Management, 52: 965-981.

Grewal, D., Monroe, K.B., \& Krishnan, R. 1998. The effects of price-comparison advertising on buyers' perceptions of acquisition value, transaction value and behavioural intentions. Journal of Marketing, 62: 46-59.

Gümüş, M. \& Öksüz, B. 2009. İtibar sürecinde kilit rol: Kurumsal sosyal sorumluluk iletişimi. Journal of Yasar University, 4(14): 2129-2150.

Hair, J.F., Lukas, B., Roberts, K., \& Lee-Lukas, S. 2014. Marketing Research. McGraw-Hill, Australia.

Henning-Thurau, T. \& Klee, A. 1997. The impact of customer satisfaction and relationship quality on customer retention: a critical reassesement and model development. Psychology \& Marketing, 14(18): 737-764.

Hu, H., Kandampully, J., \& Juwaheer, T.D. 2009. Relationships and impacts of service quality, perceived value, customer satisfaction, and image: An empirical study. The Service Industries Journal, 29(2): 111-125.

Jiang, L., Jun, M., \& Yang, Z. 2013. Customer-perceived value and loyalty: How do key service quality dimensions matter in the context of B2C e-commerce?. Service Business, 1-17. doi:10.1007/s11628-015-0269-y

Jo, W., Lee, C., \& Reisinger, Y. 2014. Behavioral intentions of international visitors to the Korean hanok guest houses: Quality, value, and satisfaction. Annals of Torism Research, 47: 83-86. 
Kim, Y. \& Lee, H. (2009). Passenger complaints under irregular airline conditions - cross-cultural study. Journal of Air Transport Management, 15(6): 350-353.

Kuo, Y., Wu, C., \& Deng, W. 2009. The relationships among service quality, perceived value, customer satisfaction, and post-purchase intention in mobile value-added services. Computers in Human Behavior, 25: 887-896.

Lobo, A., Duarte, P., Carvalho, A., Rodrigues, V., Monteiro, M.J., \& Alves, H. 2014. The association of equity, accessibility, and price with primary healthcare user's satisfaction. Western Journal of Nursing Research, 36(2): 191-208.

Loureiro, S.M.C. \& Kastenholz, E. 2011. Corporate reputation, satisfaction, delight, and loyalty towards rural lodging units in Portugal. International Journal of Hospitality Management, 30: 575-583.

Mokhtaran, M., Fakharyan, M., Jalilvand, M.R., \& Mohebi, M. 2015. The effect of service climate on perceived service value and behavioral intentions: The mediating role of service quality. Asia Pacific Journal of Tourism Research, 20(4): 472-486.

Nugroho, A.P. \& Suroto, K.S. (2015). The relationships of reputation, advertisement attractiveness, community effect with customer value and positive words of mouth of bear brand milk consumers in malang. International Journal of Management, Accounting and Economic, 2(7): 620-630.

Olorunniwo, F., Hsu, M.K., \& Udo, G.J. 2006. Service quality, customer satisfaction, and behavioral intentions in the service factory. The Journal of Services Marketing, 20(1): 5972.

Parasuraman, A., Zeithaml, V.A., \& Berry, L.L. 1985. A conceptual model of service quality and its implications for future research. Journal of Marketing, 41-50.

Parasuraman, A., Zeithaml, V.A., \& Berry, L.L. 1988. SERVQUAL: A multiple-item scale for measuring customer perceptions of service quality. Journal of Retailing, 12- 40.

Peter, J.P. \& Olson, J.C. 2010. Consumer Behavior \& Marketing Strategy, McGraw-Hill Irwin, 9. Edition. 
Pratiwi, A.R., Zhao, S., \& Mi, X. 2014. Quantifying the relationship between visitor satisfaction and perceived accessibility to pedestrian spaces on festival days. Frontiers of Architectural Research, 4: 285-295.

Ryu, K., Lee, H., \& Kim, W.G. 2012. The influence of the quality of the physical environment, food, and service on restaurant image, customer perceived value, customer satisfaction, and behavioral intentions. International Journal of Contemporary Hospitality Management, 24(2): 200-223.

Saeidi, S.P., Sofian, S., Saeidi, P., Saeidi, S.P., \& Saeidi, S.A. 2015. How does corporate social responsibility contribute to firm financial performance? The mediating role of competitive advantage, reputation, and customer satisfaction. Journal of Business Research, 68: 341350.

Savaş, H. \& Kesmez, A.G. 2014. Hizmet kalitesinin servqual modeli ile ölçülmesi: Aile sağlı̆̆1 merkezleri üzerine bir araştırma. Pamukkale Üniversitesi Sosyal Bilimler Enstitüsü Dergisi, 17: 1-13.

Schermelleh-Engel, K., Moosbrugger, H., \& Müller, H. 2003. Evaluating the fit of structural equation models: Tests of significance and descriptive goodness-of-fit measures. Methods of Psychological Research Online, 8(2): 23-74.

Sengupta, A.S., Balaji, M.S., \& Krishnan, B.C. 2015. How customers cope with service failure? A study of brand reputation and customer satisfaction. Journal of Business Research, 68: 665674.

Sivadas, E. \& Baker-Prewitt, J.L. 2000. An examination of the relationship between service quality, customer satisfaction, and store loyalty. International Journal of Retail \& Distribution Management, 28(2): 73-82.

Swaen, V. \& Chumpitaz, R.C. 2008. Impact of corporate social responsibility on consumer trust. Recherche et Applications en Marketing, 23(4): 7-33.

Tolon, M. 2007. Tüketici tatmininin yapay sinir ağları yöntemiyle ölçülmesi ve Ankara'daki perakendeci mağazaların müşterileri üzerinde bir uygulama. Gazi Üniversitesi Sosyal Bilimler Enstitüsü İşletme Anabilim Dalı Yayımlanmamış Doktora Tezi, Ankara.

Turan, A.H. \& Çolakoğlu, B.E. 2009. Yaşlı tüketicilerde algılanan marka değeri ve satın alma niyeti. Afyon Kocatepe Üniversitesi İI.I.B.F. Dergisi, 227-296. 
TÜİK, Ulaştırma İstatistikleri, http://www.tuik.gov.tr/PreTablo.do?alt_id=1051. Erişim tarihi: 25.11.2015.

Van Dun, Z., Bloemer, J., \& Henseler, J. 2010. Perceived customer contact centre quality: Conceptual foundation and scale development. The Service Industries Journal, 1-17, doi: $10.1080 / 02642060903437584$

Vera, J. \& Trujillo, A. 2013. Service quality dimensions and superior customer perceived value in retail banks: An empirical study on Mexican consumers. Journal of Retailing and Consumer Services, 20: 579-586.

Walsh, J. \& Beatty, S.E. 2007. Customer-based corporate reputation of a service firm: scale development and validation. Journal of Academy of Marketing Science, 35: 127-143.

Walsh, G., Dinnie, K., \& Wiedmann, K. 2006. How do corporate reputation and customer satisfaction impact customer defection? A study of private energy costumers in Germany. Journal of Services Marketing, 20(6): 412-420.

Wu, K-L., Chen, S-R., Ko, W-C., Kuo, S-Y., Chen, P-L., Su, H-F., \& Chang, W-Y. 2013. The effectiveness of an accessibility-enhanced multimedia informational educational programme in reducing anxiety and increasing satisfaction of patients undergoing cardiac catheterisation. Journal of Clinical Nursing, 23: 2063-2073.

Wu, H-C. 2014. The effects of customer satisfaction, perceived value, corporate image and service quality on behavioral intentions in gaming establishments. Asia Pacific Journal of Marketing and Logistics, 26(4): 540-565.

Yang, Z., Cai, S., Zhou, Z., \& Zhou, N. 2005. Development and validation of an instrument to measure user perceived service quality of information presenting web portals. Information \& Management, 42: 575-589.

Yılmaz, İ. 2012. Turizm öğrencilerinin karayolu yolcu taşımacılığı hizmetlerine yönelik algılamalar1. Anatolia: Turizm Araştırmaları Dergisi, 23(1): 73-85.

Zameer, H., Tara, A., Kausar, U., \& Mohsin, A. 2015. Impact of service quality, corporate image and customer satisfaction towards customers' perceived value in the banking sector in Pakistan. International Journal of Bank Marketing, 33(4): 442-456. 
Zeithaml V.A. 1988. Consumer perceptions of price, quality, and value: A means-end model and synthesis of evidence. Journal of Marketing, 52: 2-22. 